\title{
INFLUENCE OF CORPORATE LEADERSHIP TRAITS ON EARLY ADOPTION OF ICT FARMING SYSTEMS BY FARMER UNIONS
}

\author{
Alpha M Manjera \\ Graduate School of Business Leadership, \\ Midlands State University, Gweru, Zimbabwe
}

\begin{abstract}
The study sought to determine the effects of leadership trait towards promoting utilization of ICT farming systems for maize production in Zimbabwe. The study adopted qualitative approach and utilized 219 participants. The research also adopted an ordinal regression model to analyze the data. The study contributed the knowledge that leadership who are dominant, who are not flexible to change and conserved hinder the adoption of ICT farming systems for maize production just like leaders under small scale maize farmer union. In order to facilitate early the adoption which has taken place under the large scale maize farmer organization, farmer leadership, must possess radical, flexibility, and participatory traits to facilitate change and not inhibit change. In order to promote the early adoption of ICT farming systems in the maize value chain the farmer union leadership must be flexible and less dominance to change.
\end{abstract}

Keywords - Adjustment, Conservatism, Dominance, ICT, Process Innovations

\section{INTRODUCTION}

Based on the background provided by Rukuni (2017) in his book "History of Farming in Zimbabwe", farming, in general, is not a new concept in the Zimbabwean context. According to Butekwa and Putani (2018), farming is an old practice which is dated 230BC as black people started to use old farming tools such as stones to plough and cultivate small pieces of land during the stone-age. Farmers during that time were not innovative enough to use machineries but rather used stones to cultivate on a small piece of land in the context which is now

\author{
Michael Twum-Darko \\ Graduate Centre for Management, Cape \\ Peninsula University of Technology, \\ Cape Town, South Africa
}

referred to as "Zimbabwe". The tools used during the stone-age era around 230BC were not effective enough to plough a bigger area compared to the $20^{\text {th }}$ Century farmers (Cormican and O'Sullivan, 2014).

In terms of the agricultural process innovations farmers were focused on shifting cultivation as their major farming system and farmers in that era were doing individual farming as a method implying that they was no organization of farmers into farmer unions, neither did agricultural companies exist to support subsistence or commercialization of crop production (Chari, 2011). The main farming system in the black community was shifting cultivation and farmers were only focused on subsistence farming with no sense of commercialization. According to the CFU (2015), around 1892 white farmers found their way into Rhodesia which is now called Zimbabwe. The white farmers became the first farmers to settle and introduce a farming system which encouraged repeated cultivation on the same piece of land. White farmers as landowners who took land by force from the black people were the first to use machineries such as cultivators, mouldboard ploughs, and hoes as technologies within the farming communities. Bass (2017) citing Rukuni (2017) emphasizes that white farmers organized themselves for knowledge sharing, innovation and generation of new farming systems by establishing the first farmer association group by the name Rhodesian Farmers and Landowners' Association (RFLA).

The concept of commercialization was introduced in 1920 with the emergency of Matabeleland Farmers Association (MFA) in agro-ecological region 4 and 5 introducing a new innovative livestock farming system now called paddocking system to manage 


\section{International Journal of Engineering Applied Sciences and Technology, 2021 Vol. 6, Issue 5, ISSN No. 2455-2143, Pages 1-16 \\ Published Online September 2021 in IJEAST (http://www.ijeast.com)}

grazing lands and water systems (Chari, 2011). The white farmers in agro-ecological Regions 1 - 3 represented by the commodity association, Rhodesian Agricultural Union (RAU) merged with the Matabeleland Farmers Association (MFA) to form the first farmer union by the name Rhodesian National Farmers' Union (RNFU) which was now changed to Commercial Farmers Union (CFU) in 1978 through union members. The formation of CFU as a farmer union was intended to create corporate leadership which promoted the empowerment of farmers through policy lobbing and advocacy (Chinhamora, and Choga, 2015). After 1980 when technologies started to trickle in, Zimbabwe became the bread basket of the Southern African Development Coordinating Conference (SADCC) as it was producing and exporting surplus.

However, background information as provided by various researchers such as Rukuni and Eicher, 2012); and Chinhamora and Choga (2015) reveal that black Zimbabwean maize farmers were subsistent; producing for their families as individuals to achieve household food security without taking farming as a business. Chinhamora and Choga (2015) postulate that the black farmers adopted the concept of maize commercialization at a smaller scale but with combined effort between 1980 and 1985 during the "Growth and Equity Programme" soon after the Land Reform Programme and managed to produce commercial maize with surplus for trade and helped make Zimbabwe the bread basket of SADC. The production was not sustainable relative to the way commercial white farmers were producing under farmer unions, therefore, black farmers decided to organize themselves into a farmer union or association by the name Zimbabwe Farmers Union (ZFU) to represent the interests of the black small scale maize farmers on 19 August 1991 borrowing the culture from the white community who had done it as early as 1920. Though the black farmers organized themselves into a farmer union, in terms of the level of innovations such as irrigation utilization, farming knowledge and skills they lagged behind relative to large white maize commercial farmers under CFU. It is in line with the research by Chinhamora and Choga (2015), the lower adoption levels of innovation, to a larger extent, corresponded to failure to develop resilient strategies for early signs of climate change which led into "the 1992 Zimbabwean common drought" which affected black farming community at large relative to white maize farmers under CFU who adopted irrigation systems such as flood and sprinkler irrigation and managed to survive the erratic rains which were received during 1992 (Gomba, 2015). ZFU small scale commercial and communal farmers were critically affected during 1992 as their production was based on rain using poor retained maize seed, the critical question still remains why black farmers failed to adopt innovations.

The adoption rate of technology at communal and small scale level was as low as $2 \%$ from the black maize farmers against $30 \%$ from the white maize farmers under CFU (Chari, 2011). Black farmers noticing that it was critical to take farming at higher level through government support and taking advantage of the Economic Structural Adjustment Programme (ESAP) which sought to achieve economic recovery through export incentives and subsidies, established a second black farmer union by the name Zimbabwe Commercial Farmers' Union (ZCFU) in 1996. It intended to support large black commercial farmers with technologies such as irrigation systems, agricultural machineries and implements such as tractors, combine harvesters and planters (Chari, 2011). The production levels under the agricultural sector did not improve significantly within the black community of Zimbabwe since the introduction of ZFU in 1991 and ZCFU in 1996 as the farmers were using Indigenous Knowledge Systems (IKS), poor technologies and failed to access formal reliable marketing systems. Since the introduction of white farmer associations around 1920s market integration has always been a problem. Even from 1991 when the first black farmers' union, ZFU, was introduced, the only markets within the agribusiness sector available were government parastatals such as GMB, Pig Industry Board (PIB) and Dairibord Zimbabwe Limited (Rukuni, 2017). In addition to lack of innovative and efficient backward and forward marketing systems, farmers were producing at a higher cost due to the shortage of better inputs for better maize yields, poor agricultural skills as much of the production of commercial maize was through trial and error methods. The adoption rate of newly introduced innovative technologies such as livestock breeding systems, crop variety selection, use of machineries and irrigation systems was very low among black farmers yet black farmers demanded back larger proportion of land from the white people (Rukuni and Eicher, 2012).

Drawing back again into the history of Zimbabwe, black farmers succeeded in grabbing back larger 


\section{International Journal of Engineering Applied Sciences and Technology, 2021 Vol. 6, Issue 5, ISSN No. 2455-2143, Pages 1-16 \\ Published Online September 2021 in IJEAST (http://www.ijeast.com)}

proportion of land through the Fast-Track Land Reform Policy in 2000 and left approximately $15 \%$ of the land with innovative white farmers and approximately $90 \%$ went to black farmers who had no technologically advanced equipment and skills on farming (Hirambwa, 2018). Zimbabwe which was once the bread basket around 1980 to the late 1990s started to realize a decline in overall domestic production from both farmers under $\mathrm{CFU}, \mathrm{ZFU}$, Zimbabwe National farmers' Union (ZNFU) and ZCFU as shown below:

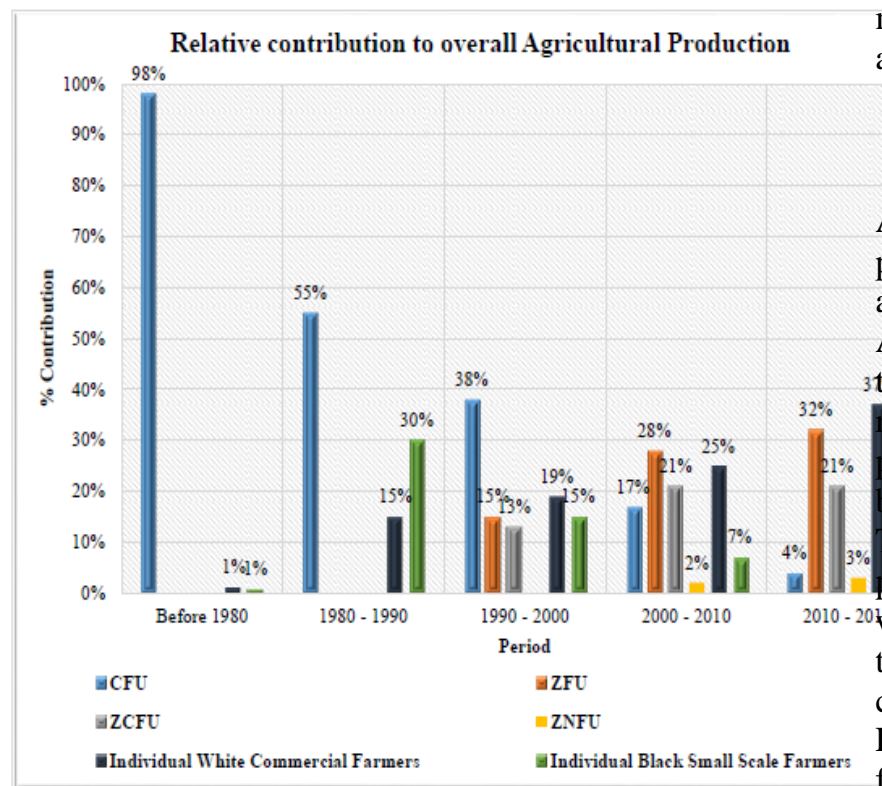

Figure 1: Contribution to overall agricultural production trends from farmer unions

Source: SACAU (2016)

The trend in the Figure 1 shows that $98 \%$ of the overall agricultural production came from organized large commercial farmers under $\mathrm{CFU}$ and the other $2 \%$ was recoded from individual commercial white and small scale black farmers prior to 1980 (SACAU, 2016). White farmers were engaged in commercialization as they had some form of technologies such as mouldboards, good cattle breeds and better seed maize varieties, pre-independence CFU contributed $98 \%$ to the overall production and Zimbabwe exported the surplus. According to Hirambwa (2018), black farmers were not yet engaged in associations but they operated as individual farmers around 1980 to 1990 and collaboratively, as small scale individual farmers, managed to contribute to $30 \%$ towards agricultural production compared to $15 \%$ from a few white farmers who survived the land invasion framework. The land acquisition policy during 1980 was reorganized to protect the few existing white and the majority black communal farmers who established farmer unions (Rukuni and Eicher, 2012). The innovation adoption level of farmers under unions was very low and the secret behind such low adoption is yet to be established. Therefore, this paper looks into the corporate leadership and its effects on the adoption of ICT. Section II shows materials and methods while III highlights the results and IV shows the conclusions and recommendations.

\section{MATERIALS AND METHODS}

According to Breslow (2015), research paradigm is a perspective that is based on the set of shared assumptions, values, concepts and practices. Although there are several paradigms or worldviews 3that structure and organize modern social work fesearch such as post-positivism, constructivism, participatory action frameworks, this research was ased on the pragmatism philosophical assumptions. The research was rooted in the pragmatism hilosophical assumptions, hence, some variables were qualified and others quantified. Leadership traits such as adjustment, dominance and conservatism were utilised as also suggested by the Leadership Trait theory from the theoretical foundations set in the second chapter of this research. The researcher chose pragmatism because pragmatism suits best a mixed methodology which involves quantitative and qualitative approaches to research. Qualitatively, the quality of innovations, the different corporate leadership styles, traits and corporate culture were also gathered at the same time from respondents concurrently. Semi-structured interview, Focus Group Discussion (FGD), semistructured questionnaire and document analysis methods were utilised to gather both qualitative and quantitative data concurrently. The research adopted convergent parallel research design were two data sets (qualitative and quantitative data sets) were analyzed separately to make generalizations from SPSS and establish themes from NVivo software. The convergent parallel research design allowed the researcher to ascertain the association between corporate leadership, corporate culture and agricultural innovations within the maize value chain by establishing ordinal logistic regression model that accommodates an integrated mixed the results from 


\section{International Journal of Engineering Applied Sciences and Technology, 2021 Vol. 6, Issue 5, ISSN No. 2455-2143, Pages 1-16 \\ Published Online September 2021 in IJEAST (http://www.ijeast.com)}

qualitative and quantitative perspective during interpretation as a triangulation method during the study. However, a sample size of 219 participants from the 37 entities in the maize value chain were considered during the study. The sample size for the study was supported by Breslow (2015) who postulates that at least $30 \%$ of the population is adequate for precision and estimation of population parameters.

In terms of the data analysis procedures, the research adopted an ordinal logistic regression models denoted by $\left(\mathrm{Y}_{1 \mathrm{t}}\right)$. However, Ordinal logistic regression Model had nominal, categorical independent variables. The table 2 below shows the independent variables to the ordinal logistic regression model and dummies or categorical levels of each variable in the model. The theoretical sources of such variables are also shown in the table below:

Table 1: Ordinal logistic regression variables

\begin{tabular}{|l|l|ll|}
\cline { 2 - 4 } \multicolumn{1}{c|}{} & \multicolumn{3}{c|}{ Corporate Leadership traits based on Leadership Traits Theorist Mann } \\
(1959)
\end{tabular}

Source: Researcher Computations

The categorical dependent variable was assigned 3 ordered values in the model early innovation adoption, late innovation adoption and laggards in innovation adoption as shown in Table 1. The dependent variable was used to regress against corporate leadership traits (Adopted from Corporate Leadership Trait Theory). The choice of this method was based on the fact that the agricultural innovation adoption (dependent variable) was an ordered variable which took the following values $(0,1$, and 2$)$ which are early innovation adoption and laggards in innovation adoption where late innovation adoption was the Reference Group. The ordered logistic regression model was utilized to identify the corporate leadership traits that promotes such behaviour of early innovation adoption, and laggards in innovation adoption as denoted by 0 and 1 reference group being late innovation adoption denoted by 2 .

\section{RESULTS REPORTING}

This section was structured in a manner that it started by the presentation of findings from questionnaires. Secondly, the questionnaire findings were integrated with findings from the interviews, focus group discussions and secondary data gathering. The last section of this objective was the discussion of findings in relation to literature.

\section{Corporate Leadership Traits under farmer unions}

The tables below presented responses from the Farmer Union employees in terms of identifying corporate cultural values each farmer union exhibit in the maize value chain.

Table 2: Corporate leadership traits under farmer unions

\begin{tabular}{|l|l|l|l|l|l|l|}
\hline \multirow{2}{*}{ Statements } & FU & \multicolumn{5}{|c|}{ Percentage Responses } \\
\cline { 3 - 7 } & & SA & A & N & D & SD \\
\hline $\begin{array}{l}\text { Leadership are } \\
\text { radical in adopting }\end{array}$ & ZFU & $10 \%$ & $10 \%$ & $0 \%$ & $40 \%$ & $40 \%$ \\
\cline { 2 - 7 } $\begin{array}{l}\text { ICT farming } \\
\text { systems. }\end{array}$ & $50 \%$ & $50 \%$ & $0 \%$ & $0 \%$ & $0 \%$ \\
\hline $\begin{array}{l}\text { Leadership is very } \\
\text { dynamic and } \\
\text { compulsive. }\end{array}$ & ZFU & $20 \%$ & $20 \%$ & $0 \%$ & $20 \%$ & $40 \%$ \\
\cline { 2 - 7 } $\begin{array}{l}\text { Leadership has } \\
\text { dominance traits }\end{array}$ & $30 \%$ & $20 \%$ & $0 \%$ & $50 \%$ & $0 \%$ \\
\cline { 2 - 7 } & ZCU & $10 \%$ & $15 \%$ & $0 \%$ & $25 \%$ & $50 \%$ \\
\hline $\begin{array}{l}\text { There is high } \\
\text { demands, of } \\
\text { adopting new ICTs }\end{array}$ & ZFU & $80 \%$ & $40 \%$ & $0 \%$ & $0 \%$ & $0 \%$ \\
\cline { 2 - 7 } & ZCFU & $0 \%$ & $10 \%$ & $0 \%$ & $50 \%$ & $40 \%$ \\
\hline $\begin{array}{l}\text { There is resistance to } \\
\text { change in adoption } \\
\text { of ICT farming } \\
\text { systems }\end{array}$ & ZFU & $90 \%$ & $10 \%$ & $0 \%$ & $0 \%$ & $0 \%$ \\
\cline { 2 - 7 } & ZCFU & $40 \%$ & $10 \%$ & $0 \%$ & $50 \%$ & $0 \%$ \\
\hline
\end{tabular}

Sources: SPSS Computations

The findings presented in Table 2 showed the leadership traits under the 2 farmer unions, ZFU and ZCFU. From the findings, $100 \%$ cumulatively who form the majority of the employees under ZCFU highlighted that their organization is characterized by radical leadership which permits adoption of ICT farming systems. Contrary to that, are $80 \%$ of the employees from ZFU who had the view that their organization does not possesses leadership with enthusiasm and emotional stability traits which create 


\section{International Journal of Engineering Applied Sciences and Technology, 2021 Vol. 6, Issue 5, ISSN No. 2455-2143, Pages 1-16 \\ Published Online September 2021 in IJEAST (http://www.ijeast.com)}

a culture of adopting ICT farming systems. Instead, majority of the employees who constitute $60 \%$ from ZFU confirmed that ZFU their organization lack leadership which is very dynamic and compulsiveness. Due to leadership's poor adaptability, farmers are now characterized by resistance to change mind-set informing maize farmers the shortcomings of ICTs in production of maize and this was highlighted by all employees under ZFU. This was different from ZCFU were 50\% highlighted that the organization is dominated by very dynamic and compulsive leaders in relation to driving ICT innovations. Based on that flexibility, $50 \%$ of ZCFU employees highlighted that there is less resistance to change in terms of diffusion of ICT farming systems.

Furthermore, the results showed that $90 \%$ employees, cumulatively from ZCFU highlighted that leadership within their organization do not exhibit dominance traits as the working environment is very participatory. This was different from responses gathered from ZFU as $75 \%$ of the employees cumulatively, confirmed that their organizational leadership exhibit dominance traits and the working environment is very controlled and structured place. Due to leadership's high dominance traits, the farmers are now hard-driving competitiveness, high demands, and achievement motives in terms of adopting new ICTs as confirmed by all employees under ZFU.

Based on the responses from the employees, ZFU leadership was found to exhibit dominance, conserved traits and lacked flexibility in change. This differed from the ZCFU who had been found exhibiting participatory, flexibility and radical traits. Such leadership traits were used to predict the early adoption of ICT farming systems under the farmer unions and results were presented in the next section.

\section{Predicting Adoption of ICT Farming Systems}

In order to account for the effects of corporate leadership traits on adoption of ICT farming systems, leadership traits, and ordinal logistic regression model presented the findings from questionnaires in this section. The results were presented on the table below:
Table 3: Analysis of agricultural process innovations and corporate leadership traits

\begin{tabular}{|c|c|c|c|c|c|c|}
\hline \multirow{3}{*}{$\begin{array}{l}\text { Categorical } \\
\text { Variable } \\
\text { Corporate } \\
\text { Leadership } \\
\text { traits }\end{array}$} & \multicolumn{3}{|c|}{$\begin{array}{c}\text { Laggards adopters } \\
\text { of innovation } \\
\text { (Group) }\end{array}$} & \multicolumn{3}{|c|}{$\begin{array}{c}\text { Early in } \\
\text { innovation } \\
\text { adoption (Group) }\end{array}$} \\
\hline & \multicolumn{3}{|c|}{ Parameters } & \multicolumn{3}{|c|}{ Parameters } \\
\hline & B & Sig & S.E & B & Sig & S.E \\
\hline $\begin{array}{l}\text { [Adjustment } \\
=0]\end{array}$ & -.021 & 0.02 & .412 & .811 & 0.00 & .124 \\
\hline $\begin{array}{l}\text { [Adjustment } \\
=1 \text { ] }\end{array}$ & $0^{\mathrm{b}}$ & . & . & $0^{\mathrm{b}}$ & . & . \\
\hline $\begin{array}{l}\text { [Conservatis } \\
\mathrm{m}=0]\end{array}$ & -.121 & 0.00 & .114 & .952 & 0.00 & .141 \\
\hline $\begin{array}{l}\text { [Conservatis } \\
\mathrm{m}=1]\end{array}$ & $0^{\mathrm{b}}$ & . & . & $0^{\mathrm{b}}$ & . & . \\
\hline $\begin{array}{l}\text { [Dominance } \\
=0]\end{array}$ & -.357 & 0.00 & .174 & .976 & 0.00 & .154 \\
\hline $\begin{array}{l}\text { [Dominance } \\
=1]\end{array}$ & $0^{\mathrm{b}}$ & . & . & $0^{\mathrm{b}}$ & . & . \\
\hline $\begin{array}{l}\text { Constant/Inte } \\
\text { rcept }\end{array}$ & 11.16 & 0.00 & $\begin{array}{c}1.31 \\
4\end{array}$ & $\begin{array}{c}8.42 \\
4\end{array}$ & 0.01 & $\begin{array}{c}1.32 \\
4\end{array}$ \\
\hline $\begin{array}{lcc} & 2 \\
\text { Likelihood }\end{array}$ & \multicolumn{6}{|c|}{$-144.12455^{*}$} \\
\hline $\begin{array}{l}\text { Likelihood } \\
\text { Ratio }(\lambda)\end{array}$ & \multicolumn{6}{|c|}{15.332} \\
\hline$\rho^{2}$ & \multicolumn{6}{|l|}{0.00} \\
\hline. $\mathrm{df}$ & \multicolumn{6}{|c|}{3} \\
\hline \multirow{3}{*}{$\begin{array}{ll}\text { Pseudo } & \mathrm{R}^{2} \\
\text { Values } & \end{array}$} & \multicolumn{2}{|c|}{ Negelkerke } & \multicolumn{4}{|l|}{.862} \\
\hline & \multicolumn{2}{|c|}{ Snell } & \multicolumn{4}{|l|}{.744} \\
\hline & \multicolumn{2}{|c|}{ McFadden } & \multicolumn{4}{|l|}{.397} \\
\hline
\end{tabular}

a. Reference Group: Late Adopters of innovation

Source: Statistical Computation, SPSS

The following empirical ordinal logistic regression model and its variables was the resultant model for estimation of early adoption ICT farming systems as influenced by corporate leadership traits such as adjustment, conservatism and dominance.

$$
Y_{1 t}{ }^{*}=8.424+0.811 X_{1 t}+0.952 X_{2 t}+0.796 X_{3 t}+u_{i t}
$$$$
\text { ....Equation (6) }
$$

Where,

$$
\begin{array}{ll}
\mathbf{Y}_{1 \mathbf{t}}{ }^{*}= & \text { Adoption of ICT farming systems } \\
\mathbf{X}_{\mathbf{1 t}}= & \text { Adjustment } \\
\mathbf{X}_{\mathbf{2 t}}= & \text { Dominance } \\
\mathbf{X}_{\mathbf{3 t}}= & \text { Conservatism } \\
\mathbf{B}_{\mathbf{0}}= & \text { Intercept/Constant } \\
\mathbf{B}_{\mathbf{1 - 3}}= & \text { Beta Coefficients } \\
\mathbf{u}_{\mathbf{i t}}= & \text { Error Term }
\end{array}
$$

Table 4: Model fitting information

\begin{tabular}{|c|c|c|c|c|}
\hline Model & $\begin{array}{c}\text { Model Fitting } \\
\text { Criteria }\end{array}$ & \multicolumn{3}{|c|}{$\begin{array}{c}\text { Likelihood Ratio } \\
\text { Tests }\end{array}$} \\
\cline { 2 - 5 } & $\begin{array}{c}-2 \text { Log } \\
\text { Likelihood }\end{array}$ & $\begin{array}{c}\text { Chi - } \\
\text { Square }\end{array}$ & Df & Sig. \\
\hline
\end{tabular}




\section{International Journal of Engineering Applied Sciences and Technology, 2021 Vol. 6, Issue 5, ISSN No. 2455-2143, Pages 1-16 \\ Published Online September 2021 in IJEAST (http://www.ijeast.com)}

\begin{tabular}{|l|r|r|r|c|}
\hline $\begin{array}{l}\text { Intercept } \\
\text { Only }\end{array}$ & 335.112 & & & \\
\hline Final & 41.024 & 412.112 & 3 & .001 \\
\hline \multicolumn{5}{|c|}{ Goodness-of-Fit } \\
\hline & Chi-Square & Df & Sig. \\
\hline Pearson & 1.475 & & .000 \\
\hline Deviance & 4.215 & 2 & .0 .03 \\
\hline
\end{tabular}

Sources: SPSS Computations

\section{a. Leadership Dominance Traits and Adoption of ICT Farming Systems}

Leadership traits were also measured in terms of dominance where these corporate leadership traits had also two dummies. Farmer unions could either make use of a bottom up or a top down orientation communication. The probability that maize farmers under farmer unions adopted ICT farming systems innovations either at an earlier stage or they did not even adopt the innovation was tested as predicted by whether they are involved in the decisions towards adoption of innovation. The results of the study showed in Table 3 that farmer unions together with their associations who are less dominative, who values a bottom up decision orientation with change are most likely to become early ICT farming systems innovation adopters with a beta coefficient of 0.976 . Therefore, the results in both Table 5 and empirical model equation (6) suggests that the probability that maize farmer as a member of a Farmer Union with a bottom up approach with change are most likely to adopt ICT farming systems innovations earlier is 0.976 signifying $97.6 \%$ chances of adopting ICT farming systems. In addition, the results of the study in Table 3 has shown that maize farmers under farmer unions who are less dominative are less likely to become laggards with reference to late adopters in adoption of ICT farming systems innovations as shown by a beta coefficient of -0.357 . This also suggests that the chances or probability that maize farmer who are flexible to change are less likely to become a laggard in innovation adoption with $35.7 \%$ chance as shown by a beta value of -0.357 .

The exponential beta values of the model was presented in Table 3 which showed how leadership traits in terms of dominate in decision towards changes influence adoption of ICT farming systems innovations. The results in Table 5 showed an Exp (Beta) coefficient value of 0.214 for maize farmers who were early ICT farming systems innovation adopters. Based on the conditions for Exp (Beta) from the model, the coefficient value of 0.214 was above zero (0) this implied that farmers who values bottom up approach to change diffusion are most likely to be adopt innovation of ICT farming systems innovations relative to those who those who are less dominate. The findings has shown that the p-values were less than 0.05 at $5 \%$ significance level, implying the findings were statistically significant. The results of the study suggests that farmers who are laggard adopters of innovation are most likely to value top down orientation. The results of the study has shown that the adoption of innovation is influenced by dominance as a corporate leadership traits. This was also confirmed in terms of the odds value, which in this case it was $0.214=$ odds change adapters/odds change resisters implying that odds (changers) is lower by $79 \%$ for laggards than late adopters.

The interviews confirmed perception on of farmer union leadership on influence of dominance in communication provision for the facilitating ICT innovations under farmer unions. In response, Respondent $\mathrm{C}$, under small scale farming organization highlighted that:

"The only way we can start to advocate for a trial in the ICT farming based system is when the government through our Ministry introduce a scheme or allocate donation fund towards our organization in terms of ICT farming systems, otherwise we will rather maintain status quo, doing our old ways of farming."

However, the response was a different from the one given by Respondent $\mathrm{D}$, the from large scale farming organization who suggested that:

"As large scale maize farmers we value new information, because we have seen that farming for the past 10 years has been hindered by information paucity. In that regard, in this modern era, we have engaged the Ministry of Information, Publicity and Broadcasting Services as proposed by our large scale membership to assist us with mobile applications and creation of our own local content to assist maize productivity."

Triangulating with findings from FGDs the researcher also confirmed the perceptions of farmers as to whether adoption of new ideas and maize production system is governed by the leadership to bring change from a value chain approach. However, the responses were as follows: 


\section{International Journal of Engineering Applied Sciences and Technology, 2021 Vol. 6, Issue 5, ISSN No. 2455-2143, Pages 1-16 \\ Published Online September 2021 in IJEAST (http://www.ijeast.com)}

"The purpose of our organization, which is why we have voted for such farming leadership is to gather donate resources such as fertilizers, seeds and chemicals for maize farming for free so that we can use such inputs to grow maize for our families at household level." According to the respondents in anonymously under small scale farmer union FGD 1 and 5

The other participants highlighted that:

"Although our organizations must represent us through lobby and advocacy, the voice must be coming from us as maize farmers, we feel sometimes that they represents their own interests by taking their own problem as our organizational problem" According to the respondents in anonymously under small scale farmer union FGD 3, 4 and 5

The above response from such focus groups suggested that small scale farmer unions dominates and do not embrace a participatory open policy or approach to facilitation of ICTs for promotion of maize production. However, the other responses further confirmed that:

"I witnessed that there is a tendency of domination, within the farmer union as much of the decisions made is [are] done outside our consultations. Sometimes we are just forced to accept things as they are without are opinions, which makes it difficult for us to comply or unite." According to the respondents in anonymously under small scale farmer union FGD 1 and 6

The researcher posed a question on the extraversion to the leadership to check how it has influenced the facilitation of ICTs for farming and responses from focus groups highlighted that:

"We are not confident with our leaders and organization as sometimes what they say is not what happens, the decision flow is top-down oriented rather than bottom-up. In other words, they think for us, it seems as if they know what we think, what we want, which is something that is always reflected the decision outcome." According to the respondents in anonymously under small scale farmer union FGD 1 and 5

The findings presented from the farmers union and agricultural companies regarding this objective has shown that various ICT farming systems were established during 2010-2016 farming seasons. However, adoption of ICT farming systems was very low due to dominancy as leadership trait. Therefore, looking at findings from analyzed ordered logistic regression and qualitative findings from interviews and FGDs the results of the study suggests that farmers who are laggard adopters of innovation are most likely to value top down orientation. The results of the study has shown that the adoption of innovation is influenced by dominance as a corporate leadership traits.

\section{b. Leadership Conservatism Trait and Adoption of ICT Farming Systems}

Leadership traits were also measured in terms of conservatism were these corporate leadership traits had also two dummies. Farmer unions could either exhibit radical traits in decisions towards change versus those who are in conserved in terms of change management decisions. The traits we used to predict the probability that maize farmers under farmer unions adopted ICT farming systems innovations either at an earlier stage or they did not even adopt the innovation. The results of the study showed in Table 3 that farmer unions together with their associations who are conserved, towards change are most likely to become early ICT farming systems innovation adopters with a beta coefficient of 0.952 . Therefore, the results in both Table 3 and empirical model equation (6) suggests that the probability that maize farmer as a member of a Farmer Union with a radical behaviour are most likely to adopt ICT farming systems innovations earlier is 0.952 signifying $95.2 \%$ chances of adopting ICT farming systems. In addition, the results of the study in Table 3 has shown that maize farmers under farmer unions who are radical are less likely to become laggards with reference to late adopters in adoption of ICT farming systems innovations as shown by a beta coefficient of -0.121 . This also suggests that the chances or probability that maize farmer who are radical with change are less likely to become a laggard in innovation adoption with $12.1 \%$ chance as shown by a beta value of -0.121 .

The exponential beta values of the model was presented in Table 3 which shows how leadership traits in terms of conservatism in decision towards changes influence adoption of ICT farming systems innovations. The results in Table 3 has shown an Exp (Beta) coefficient value of 0.162 for maize farmers who were early ICT farming systems innovation 


\section{International Journal of Engineering Applied Sciences and Technology, 2021 Vol. 6, Issue 5, ISSN No. 2455-2143, Pages 1-16 \\ Published Online September 2021 in IJEAST (http://www.ijeast.com)}

adopters. Based on the conditions for Exp (Beta) from the model, the coefficient value of 0.162 was above zero (0) this implied that farmers who are radical to change diffusion are most likely to be adopt innovation of ICT farming systems innovations relative to those who those who are conserved. The findings showed that the $p$-values were less than 0.05 at $5 \%$ significance level, implying the findings were statistically significant. The results of the study suggests that farmers who are laggard adopters of innovation are most likely to value conserved traits. The results of the study showed that the adoption of innovation is influenced by conservatism as a corporate leadership traits. This was also confirmed in terms of the odds value, which in this case it was $0.162=$ odds change adapters/odds change resisters implying that odds (changers) is lower by $84 \%$ for laggards than late adopters.

From the interviews conducted the researcher asked the participants the major cause of the low adoption of technology from a leadership perspective and the Respondent C from small scale farmer union highlighted that:

"Farming must be practical and we don't believe ICT can just improve our maize productivity, even though the Agricultural Extension Officers and the Ministry of Information, Publicity and Broadcasting Services once approached us with "Kurima Mari" mobile application which they suggested us to improve means of producing maize, we still believe we need to conserve our old ways of farming, because who has seen mobile farming working?"

As the response from the Respondent $\mathrm{C}$ has some elements of conservatism, looking from the Respondent D from large scale farmer union in a separate interview he had a different opinion. Respondent D argued that:

"The environment is relatively changing in all dynamics with globalization aspect coming in to promote our commercial maize enterprises. New means of production such as computerized Irrigation systems, drones are now key and we are keen to change only if the government has created a favorable economic policy environment."

The results gathered from farmer union during interviews were reflecting that in terms of leadership traits the small scale organization are characterized by conservatism as they do not engage other stakeholders in decision making or facilitation of adoption of innovation. This is different with the large scale maize farmers who value change, and can adapt to change. The results of the study suggests that small scale maize farmers who are laggard adopters of innovation are most likely to value conserved traits. The results of the study showed that the adoption of innovation is under small scale maize production sector influenced by conservatism as a corporate leadership traits.

\section{c. Leadership Adjustment Traits and Adoption of ICT farming systems}

Leadership traits were also measured in terms of adjustment where this corporate leadership traits had also two dummies. Farmer unions could either exhibit traits of flexibility towards change versus those who are not flexible with change. The probability that maize farmers under farmer unions adopted ICT farming systems innovations neither at an earlier stage nor they did not even adopt the innovation was tested as predicted by adjustment traits that the organization advocate for. The results of the study showed in Table 3 that farmer unions together with their associations who are highly flexible with change are most likely to become early ICT farming systems innovation adopters with a beta coefficient of 0.811 . Therefore, the results in both Table 3 and empirical model equation (6) suggests that the probability that maize farmer as a member of a Farmer Union who are highly flexible with change are most likely to adopt ICT farming systems innovations earlier is 0.811 signifying $81.1 \%$ chances of adopting ICT farming systems. In addition, the results of the study in Table 3 has shown that maize farmers under farmer unions who are highly flexible are less likely to become laggards with reference to late adopters in adoption of ICT farming systems innovations as shown by a beta coefficient of -0.021 . This also suggests that the chances or probability that maize farmer who are highly flexible with change are less likely to become a laggard in innovation adoption with $2.1 \%$ chance as shown by a beta value of -0.021 .

The exponential beta values of the model were presented in Table 3 which shows how leadership traits in terms of its flexibility towards changes influence adoption of ICT farming systems innovations. The results in Table 3 has shown an Exp (Beta) coefficient value of 0.0 .84 for maize farmers who were early ICT farming systems innovation 


\section{International Journal of Engineering Applied Sciences and Technology, 2021 Vol. 6, Issue 5, ISSN No. 2455-2143, Pages 1-16 \\ Published Online September 2021 in IJEAST (http://www.ijeast.com)}

adopters. Based on the conditions for Exp (Beta) from the model, the coefficient value of 0.084 was above zero (0) this implied that farmers who are highly flexible to adjust to change are most likely to be adopt innovation of ICT farming systems innovations relative to those who those who are less flexible. The findings showed that the p-values were less than 0.05 at $5 \%$ significance level, implying the findings were statistically significant. The results of the study suggests that farmers who are laggard adopters of innovation are less likely to be flexible with changes in terms of innovation drive relative to early adopters. Rather they prefer to preserve old ways of doing things. The results of the study showed that the adoption of innovation is influenced by adjustment as a corporate leadership traits. This was also confirmed in terms of the odds value, which in this case it was $0.084=$ odds change adapters/odds change resisters implying that odds (changers) is lower by $92 \%$ for laggards than late adopters.

The interviews also confirmed perception on how different technological skills, contribute to overall variance in innovative adoption among farmers unions. In response to such a question, Respondent $S$ in the Ministry of Information, Publicity and Broadcasting Services, highlighted that:

"The farmer unions especially small scale maize farmers were born before such ICT technologies and to talk of production idea generation, transfer and utilization via ICT has been a problem till then and now as majority are a bit conserved despite the fact that they might have mobile phones. Therefore, if making a comparison I can say large scale maize farmers' exhibits flexibility leadership traits compared to small scale maize farmers in the utilization of the ICTs."

The researcher also posed a follow-up question which sought to initiatives the government ministries implemented which indicated that the personality of farmer unions is not pleasing in terms of ICT innovations. Respondent $\mathrm{S}$ in the Ministry of Information, Publicity and Broadcasting Services justified by saying that:

"We have tried to engage farmers together with one of the seed company Seed Co and establish a hybrid production information application in Zimbabwe with the intention to promote good agronomic practices as guided by the Seed Co extension department, however, from the assessment we have done so far since 2011, we have noticed that only 5\% of the small scale has been registered to have adopted such ICT farming system and none of the small scale has ever adopted it based on the records submitted to us."

The researcher also confirmed with Respondent B in the Ministry of Lands, Agriculture, Water and Rural Settlement in separate interviews who emphasized the same points highlighting that:

"There are several ICT applications we have managed to work hand in hand with the Ministry responsible of ICT, to mention few the e-soko, eextension, Eco-Farmer, Seed Co applications requested by the agricultural companies and prominent white large scale maize farmers. These applications were designed with the intention to assist our local maize farmers in sharing and gaining new production systems from the agricultural value chain perspective"

However, to triangulate the information on ICT applications designed versus the adoption from interview by Government Ministries, the Seed Co participant highlighted in an open ended section of a questionnaire that:

"As Seed Co, we have designed an ICT platform accessed via our website, mobile phones and we have established social media platforms for information sharing, however, the feedback from farmers as users of such interfaces is at minimum as between 2010 and 2016 only 9-10\% of the large scale maize farmers visited such platforms and those were the statistics shared with the Ministry of Lands, Agriculture, Water and Rural Settlement and Agriculture."

In addition, a follow-up from Seed Co to seek for clarity on above points was done and the Participant $\mathrm{V}$, under Seed Co further highlighted the following:

"However, based on the survey we did to find the main attributes to low adoption of such ICT innovation, we picked that small scale maize farmers under unions are not comfortable to get advise via ICT applications, they require a person in physical and even their leadership advice their members only to render anything that comes via ICT as not authentic source."

The researcher also gathered data from the presidium of farmer unions using interviews and maize farmers 


\section{International Journal of Engineering Applied Sciences and Technology, 2021 Vol. 6, Issue 5, ISSN No. 2455-2143, Pages 1-16 \\ Published Online September 2021 in IJEAST (http://www.ijeast.com)}

using FGDs to triangulate the findings gathered from the government ministries who participated in this research.

The researcher posed a probing a question to check how the leadership adjustment has influenced the adoption of ICT and the Responded D, the leader under large scale farmer union further postulated that:

"In response to climate change we are acknowledging that there is need to develop a radical spirit of self-resource mobilization from the organizational level and advocating for change in all structures and speak ICT advancement for better production systems as a resilience strategy."

From such contributions it was noted from the top leadership perspective that large commercial farmer union adjust to the changes at a faster rate than small scale maize farmers. To confirm that, the researcher posed a question also to check how the leadership adjustment has influenced the adoption of ICT from a small scale perspective and the Respondent $\mathrm{C}$ from ZFU highlighted a different opinion from the large scale farmer union by suggesting that:

"Most of our members are small scale maize farmers who are not technologically sound, in the sense that they are lagged behind in terms of understanding ICTs therefore, adjusting to move with the technological environment is still a dream from our perspective"

The researcher sought clarity from the Respondent C under small scale farmer union to provide an example which signifies that small scale farmers are still lagged with technology regardless of efforts done so far to ensure availability of the technology. The respondent expounded that:

"As an organization have tried to work with Econet with their ICT application "Eco-Farmer" which sought to provide information of the climate smart agriculture sharing information on climate change, best production techniques however, up to now I can only say the technology was not embraced by even $10 \%$ of our members as we feel it's too early for us to climb up that ladder."

Based on the secondary data gathered from agricultural companies into ICT farming systems the following were common agricultural process innovations made available for maize production between 2010 and 2016:

Table 5: Results from reports on ICT farming systems for maize production

\begin{tabular}{|l|l|l|}
\hline \multicolumn{1}{|c|}{$\begin{array}{c}\text { Company } \\
\text { Category }\end{array}$} & Author & \multicolumn{1}{c|}{$\begin{array}{c}\text { Findings in terms of } \\
\text { Type of Farming } \\
\text { Systems }\end{array}$} \\
\hline $\begin{array}{l}\text { Insurance } \\
\text { Companies } \\
\text { i.e. Econet } \\
\begin{array}{l}\text { Wireless (Eco } \\
\text { farmer) }\end{array}\end{array}$ & $\begin{array}{l}\text { ZFU } \\
(2018)\end{array}$ & $\begin{array}{l}\text { Eco farmer weather } \\
\text { based insurance, } \\
\text { weather and } \\
\text { agronomic } \\
\text { information for maize } \\
\text { farmers }\end{array}$ \\
\hline $\begin{array}{l}\text { ICT Extension } \\
\text { Companies i.e. } \\
\begin{array}{l}\text { WHH, Presque, } \\
\text { Seed Co }\end{array}\end{array}$ & $\begin{array}{l}\text { MLAWR } \\
(2018)\end{array}$ & $\begin{array}{l}\text { Kurima Mari (e- } \\
\text { extension application) }\end{array}$ \\
\hline $\begin{array}{l}\text { ICT technical } \\
\text { equipment } \\
\text { companies i.e. } \\
\text { iFarm }\end{array}$ & $\begin{array}{l}\text { UNDP farming } \\
\text { application }\end{array}$ \\
\hline
\end{tabular}

For reference of the title of the actual sources refer to the reference list. From the secondary data sources Eco farmer is one of the farming system which was introduced by Econet wireless Pvt. Ltd to assist maize farmers with information on weather and agronomic information to adapt to climate change. The ICT based farming system also provided information like expected rains, effective dates for rains and temperature to maize farmers for better informed production decisions (ZFU, 2018). In any case, a maize farmer's maize has been severely damaged with drought or a natural disaster such farmer will be covered though maize insurance under the ICT based system.

In addition, SNV (2015) suggests that Kurima Mari (e-extension) is another android application designed to link maize farmers to local, regional input and output markets. The platform also was updated in 2018 to provide information of agronomic practices and act as a knowledge generation and sharing center among maize farmers (MLAWR, 2018). Seed Co also publicized their ICT farming application with conservation farming techniques to provide extensive knowledge on fertilizer, herbicide and seed maize variety use for maximum productivity. The last reviewed report was the UNDP (2018) report which highlights that iFarm, a wholly owned company in Zimbabwe, introduced drones which can be used for land mapping, and field scouting after maize infestation by army worms and locusts was initially 


\section{International Journal of Engineering Applied Sciences and Technology, 2021 Vol. 6, Issue 5, ISSN No. 2455-2143, Pages 1-16 \\ Published Online September 2021 in IJEAST (http://www.ijeast.com)}

noted early 2013. However, although the findings were showing that companies are creating innovation and farmers are not adopting such innovations, the discussion part of this research objective is in the next section which provided the answer to whether with such agricultural process innovations what might be influencing the adoption of such technologies. Based on findings presented from an ordered logistic regression, interviews and FGDs, the results of the study suggests that farmers who are laggard adopters of innovation are less likely to be flexible with changes in terms of innovation drive relative to early adopters. Rather they prefer to preserve old ways of doing things. The results of the study showed that the adoption of innovation is influenced by adjustment as a corporate leadership traits.

\section{d. Interpretation of the Overall Model in terms of Goodness of Fit of the Model}

In order to present and interpret the goodness of fit of the ordinal logistic regression model the methodology chapter had proposed the several methods in determination of goodness of fit. This section provides interpretation of goodness of fit based on 4 methods namely likelihood ratio index $\left(\rho^{2}\right)$, Pearson and Deviance, Pseudo $\mathrm{R}^{2}$ Values and lastly based on the Final Model. The interpretation of findings was as follows:

\section{i. Interpretation of Goodness of Fit based on likelihood ratio index $\left(\rho^{2}\right)$}

Results in Table 4 showed the likelihood ratio index $\left(\rho^{2}\right)$ value of 0.01 and since this value was not equal to zero but slightly above 0 the results implied all the slope of coefficients ( $b_{i}$ 's) were statistically significant. Based on this results it can be concluded that the ordinal logistic regression model was fit enough to predict adoption of ICT farming systems as predicted by corporate leadership traits or personalities such as adjustment, dominance and conservatism.

\section{ii. Interpretation of Goodness of Fit based on Pearson and Deviance}

Pearson and Deviance goodness-of-fit tests were utilized based on the following stated null hypothesis for testing goodness of fit:

$\mathbf{H}_{0}$ : The model is adequately fit
The findings in Table 4 showed a significance value which was less than 0.05 the conditions to qualify for goodness of fit were statistically met suggesting that the model was also fit enough to predict adoption of ICT agricultural process innovation as explained or predicted by corporate leadership traits or personalities such as adjustment, dominance and conservatism.

\section{iii. Interpretation of Goodness of Fit based on the Final Model}

Goodness of fit was also determined on the basis of final model against the null model as estimated in the SPSS. Such test was based on the following hypothesis from the model itself:

Ho: $_{0}$ There is no significance difference between null model and final model.

The results in Table 4 showed p-value of 0.01 which was less than 0.05 , implying that the final model is more significant than the null model, the condition for goodness of fit of the model.

\section{iv. Interpretation of Pseudo $R^{2}$ Values}

The results of the study in table 3 the following values were obtained Negelkerke value (0.862), Cox and Snell (0.744) and McFadden value (0.397) which suggests that the positive variations in the ICT farming systems were explained by corporate leadership traits such as adjustment, conservatism and dominance. Furthermore, for McFadden Test Rule of thumb must be 0.2-0.4 for goodness of fit (Ralws, 2016). However, since the results showed a McFadden Test value of 0.397 this also suggested that the model was fit enough to predict agricultural process innovation.

\section{RESULTS DISCUSSION}

There are leadership traits which corporate leaders under farmer unions have adopted to determine the climate as a corporate behaviour for adopting change and leading. The results of the study showed that leadership traits as adopted from Mann Theory play a critical role in predicting adoption of ICT systems. Qualitative data was gathered on level of innovation production within ICTs and Machinery provider's companies revealed that the companies such as iFarm have produced farming GPS Drones for field pest monitoring, yields estimation and GIS field size 


\section{International Journal of Engineering Applied Sciences and Technology, 2021 Vol. 6, Issue 5, ISSN No. 2455-2143, Pages 1-16 \\ Published Online September 2021 in IJEAST (http://www.ijeast.com)}

mapping tools. Companies such as Barzem, Cochrane, Solar Tech, Drip Tech and Southern Trading Co have developed various computerized center pivots and drip irrigations for efficient irrigation, farming methods but the level of utilization of such innovations among farmer unions is very poor as shown by the results of the study. Although, the adoption of ICT systems for maize production in the Zimbabwean maize value chain was regarded as low, the variation between small and large scale maize farmers was noted from their responses during data analysis. Under this objective the following themes were established:

\section{a. Adjustment as a leadership trait towards early adoption of ICT farming systems}

The results from qualitative data gathered from interviewing presidium and FGDs conducted with maize farmers under the two farmer unions has shown that the majority of maize farmers who have adopted ICT farming systems are large scale maize farmer union relative to small scale maize farmers union. The results showed that large scale maize farmers adopted Kurima Mari-ICT extension and eSoko as farming system which assisted them with better agronomic practices to adapt to climate change during 2012 and 2016 seasons. In order to test whether the identified corporate leadership traits had a contributing factor, the results from ordinal logistic regression model has shown that in terms of adjustment, small scale maize farmers who are not flexible with adoption of ICT farming systems became part of the laggards group. This arose from the idea that the majority of the small scale maize farmers preferred their old ways of doing farming as the same ethnocentric culture noted from biochemical agricultural product innovation.

Contrary to the small scale maize farmers' decision to adopt ICT influenced by failure to adjust as a leadership trait, large scale maize farmers were adjusting to change resembling early adopters' group. A culture of late and laggards under small scale farming union can be explained in literature by Yukl (2016) who posit that leadership which fails to adjust on their own lack idealized influence which is the key attribute of a leader to inspire followers to take their leader as a role model. The argument by Yukl (2016) is also evident from the findings gathered using a Focus Group Discussion when members under small scale farmer union highlighted that they did not adopt ICT farming systems as their leaders were not leading by in the adoption of technology. The findings highlighted that small scale farmer union prefer old ways of farming and are ethnocentric with technology. The idea of leadership influencing culture of early innovation adoption is also supported by Sharma (2016) who suggests that the leadership traits must be idealistic to create corporate cultural values that inspire, establish sense, and engender a sense of purpose amongst followers under farmer unions.

Large scale farmer union leaders adjust to changes and are highly flexible to change which has seen majority becoming early innovation adopters and also from a theoretical background is Albert Bandura in his theory Social learning where he posits that leaders must understand that followers learn and adopt through observation, modelling and imitation (Max, 2016). The views by Bandura are supported by Sharma (2016) who advocates for charismatic leaders who instill self-confidence onto others. It is their demonstration of confidence in a follower's preparedness to make self-sacrifices and an aptitude to undertake exceptional goals which is an influential rousing force of idealized influence and rolemodelling behaviour (Blad, 2015). Such traits were of self-sacrifices were noted from the large scale farmer union leaders who are making use of their own generated resources to adjust to changes in the farming society and business. Based on that fact the results of the study has shown that leaders with confidence in corporate players can secure great accomplishments in terms of facilitation of innovations. Leaders with idealized influence are endowed with a constructive sense of selfdetermination.

\section{b. Dominance as a leadership trait towards early adoption of ICT farming systems}

In 2015 another ICT farming system, Eco-Farmer was launched between farmer unions and Econet to assist farmers with weather information and maize crop insurance to hedge against losses of maize under climate and economic changes. Farmers were encouraged by the extension officials to take up the farming system as it was key in managing maize production risks associated with pest infestation and prolonged droughts. This was picked from the qualitative results that fall army worms and locusts affected almost $75 \%$ of the maize produce and farmers were advised to invest in insurance via platforms such as Eco farmer. 


\section{International Journal of Engineering Applied Sciences and Technology, 2021 Vol. 6, Issue 5, ISSN No. 2455-2143, Pages 1-16 \\ Published Online September 2021 in IJEAST (http://www.ijeast.com)}

From the qualitative data presented, the agricultural companies had highlighted that small scale maize farmers perceive insurance via such ICT platforms as a costs rather than benefits which was not the case when the data was gathered from the farmers. The maize farmers, both small scale and large scale maize farmers highlighted that the information is not shared within their organization with the external stakeholders and even other farmers. The major problem noted was information paucity among farmers as adopters as the members felt that their organization do not exhibit a culture of involvement. Based on such responses, the results of the study noted that almost all farmer union's exhibits dominance as leadership trait. Converging such qualitative findings, the findings from the corporate leadership trait model it was noted that maize farmers with dominance characteristics who value top down communication might become part of laggards in terms of ICT farming systems adoption. In this case since the small and large scale maize farmer unions exhibited such dominance characteristics they were negatively impacted in terms ICT farming systems.

The results showed that both large and small scale farmer unions make use of top down communication through at different stage within the organization. Large scale farmer union make use of top down when communicating with members internally and bottom up along the value chain. This was found to be different from small scale farmer union which make use of top down internally and across the value chain. Based on such findings ZFU as a small scale farmer union was found to be constrained in terms of adoption of ICT farming systems as there is no flexibility yet to improve early adoption of innovation Murrey (2014) from literature point of the view who suggests that collaboration and not individualized considerations must be taken as primary traits. Such leaders with dominance will eventually alternate from participatory to authoritarian style which hinders innovation adoption. In short, fundamental elements of individualized consideration consist of reassurance, caring for and coaching of individuals and an open and consultative approach and such approach is key for early adoption of innovation within the maize value chain. Lastly, the results of the study showed that the small scale farmer union maize farmers and their leaders are disconnected from the mission yet Avolio and Bass (2015) is of the view that developing the consciousness of followers, aligning them towards the organizational mission and vision, and motivating others in understanding and pledging to the vision is a key dimension of creating early adoption of ICT farming systems.

\section{c. Conservatism as a leadership trait towards early adoption of ICT farming systems}

The farmer leaders under the farmer unions were assessed in terms of conservatism as a leadership trait towards adoption of ICT farming systems and the results from the ordered logistic regression model has shown that farmer leaders who exhibit and advocate for a radical change were likely to be early adopters and farmer leaders who exhibit conserved culture were likely to hinder the adoption of ICT farming systems. This can be noticed from the small scale maize farmer leaders who are ethnocentric and who preferred to preserve old farming systems such as physical extension system relative to large scale maize farmer leaders who even advocate for internet farming knowledge on agronomic practices and seed maize bio-chemical innovations for improving maize production, in a modern way. It was noted that small scale maize farmer leaders prefer the use of manual farming systems as they have proved to be effective during the old days although the large scale view change as the solution to low productivity in the agricultural sector. These findings are in line with Rukuni (2017) who affirms that small scale maize farmers learn from their experiences yet large scale maize farmers learn from newness. Such leaning experiences can be tracked from the organizational leadership where large scale leadership are radical and small scale are conservative in terms of traits as shown in the results.

Max (2016) suggests that Intellectual Stimulation coupled with radical culture is key for the adoption of innovation at earlier pace. Leaders with characteristics of intellectual stimulation are those who intellectually stimulate followers, engender creativity and accept challenges as part of their job. They maintain their emotional balance, and rationally deal with complex problems. From the study the culture of dependency syndrome can be traced from the small scale farmer union leadership in the research who specified that their members together with them as leaders are have survived out of free hand-outs and sustaining maize production is also through input support schemes which the government has been offering to small scale maize farmers without a significant change. Based on literature by 


\section{International Journal of Engineering Applied Sciences and Technology, 2021 Vol. 6, Issue 5, ISSN No. 2455-2143, Pages 1-16 \\ Published Online September 2021 in IJEAST (http://www.ijeast.com)}

Grad (2019), conserved leaders cultivate the similar dependency skills in their workers and farmers as well. Radical leaders on their own as reflected large scale farmer union create self-sustaining strategies including developing problem solving techniques in the followers for making complex decisions, reflecting a mutual consensus between leaders and corporate key players. Such a radical leadership trait has been noted to have an early adoption sustaining effect among farmers as literature by House and Shamir (2013) has suggests that radical leadership traits has been seen improving the mentoring, coaching, morale-building strengths of individualized consideration which is key for early innovation adoption. From a theoretical approach the Great Man Theory as cited in Brans (2012) pinpointed that effective leaders possessed certain traits such as radical behaviour that other people did not possess. However, the results revealed that in order to create early adopters leaders must have radical behaviour to change, must adjust to change and must create a participatory environment.

\section{CONCLUSIONS AND RECOMMENDATIONS}

The study showed that there are leadership traits which corporate leaders under farmer unions have adopted to determine the climate as a corporate behaviour for adopting change and leading. The conclusions on this objective were done based on the influence of corporate leadership traits towards the adoption of ICT farming systems as agricultural process innovations within the maize value chain:

\section{a. Adjustment Traits towards adoption of ICT Farming Systems}

From the background to the study, the literature had pinpointed that all farmers are not flexible to change but the study revealed that large scale maize farmers under ZCFU have adjusted to climate and economic change and are now using ICT farming systems such as e-extension and e-soko. In addition, the study has revealed that ZFU farmer leaders are not flexible to change as they preferred their old ways of doing farming. The study has concluded that if the ZFU adjusts to change, there are $81.1 \%$ chances of such maize farmers becoming early adopters of ICT farming systems.

\section{b. Dominance Traits towards adoption of ICT Farming Systems}

The study has revealed that the two farmer unions, ZFU and ZCFU, exhibit dominance traits and based on such traits, the adoption of ICT farming systems are constrained. This was noted in several ICT farming systems such as Eco-Farmer which were launched between farmer unions and Econet to assist farmers with weather information and maize crop insurance to hedge against losses of maize under climate and economic changes. The leadership under the farmer unions did not created a culture for adoption of such agricultural process innovations as the communication channel was rigid and leadership did not involve their members who are maize farmers in such innovations. Based on such results, the study concluded that if the maize farmers under both ZFU and ZCFU continue with such dominance traits, this will negatively influence the adoption of innovation. However, the study has concluded that if the ZFU removes dominance, there are $95.2 \%$ chances of such maize farmers to become early adopters of ICT farming systems

\section{c. Conservatism as a Trait towards adoption of ICT Farming Systems}

The study has shown that small scale maize farmer leaders under ZFU prefer to preserve old farming systems such as physical extension system, relative to large scale maize farmer leaders who even advocate internet farming knowledge on agronomic practices and seed maize bio-chemical innovations for improving maize production in a modern way. It was noted that small scale maize farmer leaders under ZFU prefers use of manual farming systems as they have proved to be effective during the old days although the large scale view change as the solution to low productivity in the agricultural sector. This was different when it comes to the large scale maize farmers under ZCFU were a radical behaviour from the leaders was noted when it comes to facilitating agricultural process innovations among large scale maize farmers. Based on such results, the study concluded that if the ZFU leaders continue with such a conserved trait, this will negatively influence the adoption of ICT farming system. The study has concluded that if the ZFU adopt radical traits to change there is $79.6 \%$ chances of such maize farmers to become early adopters of ICT farming systems

In order to improve the adoption of ICT farming system as an agricultural process innovation by farmer unions in the maize value chain the following recommendations were put forward to improve 


\section{International Journal of Engineering Applied Sciences and Technology, 2021 Vol. 6, Issue 5, ISSN No. 2455-2143, Pages 1-16 \\ Published Online September 2021 in IJEAST (http://www.ijeast.com)}

facilitation of innovation within the maize value chain:

The farmer union leadership must embrace flexibility and radical traits to change as such traits has been proven from both empirical researches and literature to be effective in influencing a positive culture towards adoption of innovation. To promote diffusion of ICT farming systems, farmer unions must engage workshops and leadership trainings on effective leadership traits based on consultants or by making use of success stories which can capacitate farmer union leadership on the effective leadership traits for promoting diffusion of ICT farming systems among maize farmers.

Cost effective informal trainings and education methodologies which cover a wide spectrum such as study circle method in local language can be effected at small groups of 10-15 members to educate maize farmer leaders on effective leadership traits and the impact of such traits on the adoption of agricultural process innovations. The cost and benefit of ICT farming systems can be documented in study circle books which can be shared among group participants together with leadership experiences to promote diffusion of ICT farming systems. Such tasks of establishing study circle groups and materials can be done by the Ministry of Lands, Agriculture, Water and Resettlement in conjunction with other NGOs which promote innovation systems in the maize value chain of Zimbabwe.

To improve the adoption of ICT farming systems as agricultural process innovations from a global and regional level, the Government of Zimbabwe through Ministry of Finance and Ministry of Industry and Commerce must create policy environment that permits farmer unions leadership to embrace both regional and global integrations to promote investment in ICT farming systems. Such international skills if acquired and shared among Zimbabwean maize farmers will bring a paradigm shift from local orientation to global orientation.

\section{REFERENCES}

[1] Bass, B.M, (2017). Role of Self Leadership. .Business Innovation, (pp.31-32).

[2] Blad, H., (2015). Business Open Learning Archive: Organizational culture, (pp. 2-4).
[3] Brans, G., (2012). Economic Development for Sustained Growth. Leadership Forum, (pp.1518).

[4] Breslow, V.T., (2015). The Foundations of Social Research: Meaning and Perspectives in the Research Process, 3rd edition. London: Sage Publications, (pp. 45-51).

[5] Butekwa, K., and Putani, B., (2018). Functions of Malawian Innovation Systems. A new approach for analyzing technological change. Development Studies, 3(2), (pp.12-18).

[6] CFU, (2015). Adoption of levels of maize and wheat technologies in East Africa: Synthesis of Southern African adoption studies. SADC: CIMMYT, (pp. 12-13).

[7] Chari, T., (2011). Innovation in the Twenty-First Century. Disease and Globalization, Palgrave, Macmillan. Health Economics, 2(2), (pp.7-15).

[8] Chinhamora, C.J., and Choga, J.W., (2015). Strategic human resource practices and innovation performance the mediating role of knowledge management capacity. Business Research, (pp.87-88).

[9] Cormican, H., and O'Sullivan, W., (2014). A better way to innovate. Business, (pp. 12-13).

[10]FAO, (2018). Zimbabwean Production Status under Climate Change during 2010-2018. Zimbabwe: Agricultural Extension Officers, (pp. 2-4).

[11]FAO, (2017). FAO Statistical Yearbook 2017. Harare: FAO, (pp.3-4).

[12]FAO, (2018). Innovation Food Security and Rural Livelihoods. Harare: FAO, (pp.8-10).

[13] Gomba, D., (2015). Migration and agricultural change, the case of smallholder agriculture in highland Ecuador. Human Ecology, (pp.21-28).

[14]Grad, C.G., (2019). Entrainment, Pace, cycle, and rhythm in organizational behaviour. Research in organizational behaviour. Change Management, (pp.251-284).

[15]Hirambwa, K., (2018). Decision making framework for tender evaluation and contractor selection in public organizations with risk considerations. Socio-economic Planning Sciences, (pp.1-12).

[16]House, G. and Shamir, K., (2013). Household adoption behaviour of soil conservation, the case of North Pare and West Usambara Mountains of Tanzania. Economics, (pp.17-19).

[17] Marambanyika, T., (2016). Innovation speed and radicalness inversely related. Management, (pp.533-547). 
[18]Max, B., (2016). Culture and organizational learning. Management Inquiry, (pp.373-390)

[19] Murrey, Z.T., (2014). Modern seed maize varieties, productivity and sustainability. Agricultural Economics, (pp.54-66).

[20]Rorbarch, D.C., (2015). Zimbabwean Agricultural Revolution. Harare: UZ Press, (pp.24-33).

[21]Rukuni, M., (2017). Adoption of Technology in Zimbabwe, The Productivity Dilemma Revisited. Technology, (pp.12-18).

[22]Rukuni, M., and Eicher, S.G., (2012). Process Management and Organizational Adaption, the Productivity Dilemma Revisited. Management, (pp.135-138).

[23]SACAU, (2016). Innovation Status under SACCAU Leadership. Zambia: We-Effect, (pp.3-9).

[24] Saunders, D., (2012). Reliability and Validity in Qualitative Research. Newbury Park, California: Sage Publications, (pp.11-14).

[25] Sharma, B., (2016). Handbook of organizational culture and climate. Economics, (pp.21-22).

[26] Taridzanai, P., (2014). Aspect of innovation theory based on knowledge-management, International Information Management, (pp.121$139)$.

[27]UNDP, (2018). Insignia corporate culture under Farming sector. Accra in Ghana: United Nations, (pp.15-16).

[28] Yukl, G., (2016). Leadership in organizations. Leadership and Governance, (pp.11-17). 